\title{
Abrasive wear behaviour of nano-TiN coated AISI D3 tool steel
}

\author{
Mine Sulak', Volkan Onar ${ }^{2}$, Arzum Işıtan ${ }^{2 *}$, Hakan Öz², Yusuf Abdulkadir Ali² \\ 'Science Education Department, Pamukkale University, Denizli, Turkey, ${ }^{2}$ Mechanical Engineering Department, Pamukkale University, Denizli, Turkey.
}

Orcid: M. Sulak (0000-0003-I300-866I), V. Onar (0000-000I-6585-I98X), A. Işıtan (0000-0002-5228-9788),

H.Öz (0000-0003-4243-5I28), Y.A. Ali (0000-0002-3659-95I6)

\begin{abstract}
In this study, the effect of nano-TiN layer obtained by PVD method on tribological behaviour of $X 210 \mathrm{Cr} / 2$ (I.2080, AISI D3) cold work tool steel was investigated. Coating process was carried out by cathodic-arc PVD method using $200 \mathrm{~V}$ voltage, $350^{\circ} \mathrm{C}$ temperature, $4 \times 10^{-4} \mathrm{mbar}$ pressure, and $50 \mathrm{~A}$ current application conditions. The characterization of the coating was carried out by FESEM and SEM-EDS analysis. The coated and uncoated samples were subjected to abrasive wear test against to $220 \mathrm{mesh}$ sandpaper under 3 different loads (5, 10, and $20 \mathrm{~N})$. The tests were applied at three different sliding distances (100 m, $200 \mathrm{~m}$, and $600 \mathrm{~m}$ ) keeping the sliding speed as constant at $2,6 \mathrm{~m} / \mathrm{s}$. For uncoated samples, while the applied load increased from $5 \mathrm{~N}$ to $20 \mathrm{~N}$, the approximate wear loss increased by 10 and 8.5 times, respectively. The approximate wear loss increased by 2.2 and 12.2 times, respectively in nano- $\mathrm{TiN}$ coated samples. When compared to the coated and uncoated samples, the wear loss values obtained in the coated samples at sliding distances of $100 \mathrm{~m}$ and $200 \mathrm{~m}$ differed greatly from uncoated samples, under same conditions almost $100 \%$. However, when the sliding distance reached $600 \mathrm{~m}$, the gap started to close and the gap decreased to $30 \%$. Under the same conditions, the wear rate of the coated samples decreased up to 15 times compared to uncoated samples.
\end{abstract}

Keywords: AISI D3; Titanium nitride; Cathodic-arc PVD; Films; Wear resistance

\section{Introduction}

Thin films are particularly preferred for parts or tool surfaces that are subject to wear and corrosion, and reduce thermal and mechanical loads on the tool by reducing the coefficient of friction between the tool and the workpiece and affecting the thermal flow in the contact zone [1]. Thin films can be formed on metal surfaces by many different methods, such as PVD (physical vapor deposition), CVD (chemical vapor deposition), plasma spray, plasma nitridation, ion implantation, and diffusion-based methods [2].

Theoretically, it is possible to obtain many kinds of coatings by PVD method. It does not adversely affect the mechanical properties of the steel material since the deposition temperature is less than $600^{\circ} \mathrm{C}$ during the PVD process. The most important variables affecting the structure of the thin film obtained by PVD method can be listed as the structure of the part to be coated, coating thickness, coating temperature, and application pressure [2], [3], [4].

Metals and alloys, semiconductors, superconductors, and polymers can be coated via PVD [5]. PVD techniques can be examined under three main groups: Evaporation, Sputtering, and Plasma forming. The points separating these techniques are the application of evaporation by separate methods, the application of a negative potential to the part to be coated relative to the vacuum chamber (BIAS), and the usage of plasma. One of the commonly used evaporation techniques is the cathodic-arc evaporation system. With this technique, a high deposition rate is achieved. And also, this method allows the production of homogeneous thin coatings with high adhesion at low coating temperatures [2], [4].

The coating can be consist of simple compositions such as carbides ( $\mathrm{TiC}, \mathrm{SiC}, \mathrm{HfC}, \mathrm{ZrC}, \mathrm{VC}$ ), nitrides (TiN, HfN, $\mathrm{ZrN})$, oxides $\left(\mathrm{TiO}_{2}, \mathrm{ZrO}_{2}, \mathrm{Al}_{2} \mathrm{O}_{3}, \mathrm{SiO}_{2}\right)$, sulfides $\left(\mathrm{TiS}_{2}\right.$, $\mathrm{MoS}_{2}, \mathrm{MoS}_{3}$ ). It can be as various combinations of these $((\mathrm{TiAl}) \mathrm{N}$ and $\mathrm{Ti}(\mathrm{C}, \mathrm{N}))$, and multilayer compositions $\left(\mathrm{TiC} / \mathrm{Al}_{2} \mathrm{O}_{3} / \mathrm{TiN}\right)$, also [5].

Since it has a combination of high hardness, very good thermal and chemical resists, titanium nitride (TiN) coatings are most commonly applied especially for coating of tools by PVD $[5,6,7,8]$. Some studies indicate that TiN and TiAlN coatings produced by cathodic arc-evaporation techniques showed lower friction coefficient and lower wear rate than those of AlTiN and CrAlN coatings [7]. The TiN coating has a higher corrosion resistance than $\mathrm{CrN}$, TiN, and TiAlN in the anodic environment than in the cathodic environment [9]. 
Nanostructures obtained by many different production methods are used in many different fields such as drug release, self-cleaning fabric, flexible and high-strength materials, and nano-sized machinery manufacturing [10]. Nowadays, the acceleration of the researches on nanotechnology and obtained extraordinary features it provides, are increased the capacity of the machinery-manufacturing sector to meet specific requirements in that subject in the world. These requirements include increasing the resistance of the products against chemical and physical environment and loading conditions, making them more environmentally compatible and longer lasting, and increasing their quality properties. With nano coatings, a wide range of functions and new features can be imparted to the surfaces. Some features of them can be simplified as follows [11]:

a) Mechanical properties (e.g tribology, hardness, scratch resistance)

b) Thermal and chemical properties (e.g heat resistance and insulation, corrosion resistance)

c) Electronically and magnetic properties (e.g magneto resistance, dielectric)

d) Biological properties (biocompatibility, anti-infective)

Marani et al. [12] obtained that the use of nanocoatings in tillage systems has a much lower coefficient of friction and nine times less adhesion than other surfaces like steels. Vereschaka et al. [13] obtained that a nanostructured and multi-layered coated tool's life exceeded by 3 times the tool life of an uncoated tool, and by more than
2 times the tool life of a tool with standard coating. In the study by Wang and Lin [14] investigated the performance of nano-TiN coated stainless steel cathodes and obtained that improving electrode performance in electrochemical wastewater treatments.

The obtained properties can be used especially in preventing wear and corrosion damages of machinery and equipment, increasing the load carrying capacity of soft materials, and thermal insulation of turbines and engines [11]. Tool steels are generally preferred for molds' and tools manufacturing since they have high strength and hardness [15]. Corrosion and wear reduce the life-cycle of both machine parts and molds used to shape machine parts. Moganapriya et al. [16] reported that nano layered insert prevents the propagation of machining cracks, tool flank wear, and surface roughness. Using nanocoatings, energy consumption can be decreased and tool lifespan can be can increased [12].

This study investigated the abrasive wear behaviour of nano-TiN coated by cathodic-arc PVD method on X210Cr12 (1.2080, AISI D3) cold work tool steel. Characterization of coated and uncoated samples was performed by FESEM and SEM-EDS analysis.

\section{Material and Method}

AISI D3 (X210Cr12, 1.2080) high carbon and high chromium cold work tool steel was used in the experiments as substrate material. The chemical composition of the test material can be seen in Table 1.

Grinding operations were carried out on the samples with

\begin{tabular}{|c|c|c|c|c|c|c|}
\hline Element & C & $\mathbf{S i}$ & Mn & $\mathbf{P}$ & $s$ & $\mathrm{Cr}$ \\
\hline Amount (wt \%) & $1.90-2.20$ & $0.10-0.40$ & $0.15-0.45$ & $\leq 0.030$ & $\leq 0.030$ & $11.0-13.0$ \\
\hline \multicolumn{7}{|c|}{ Table 2. Wear Test Conditions } \\
\hline Specimen number & Coated & bated $(C / U)$ & Test load, $\mathrm{N}$ & Test distance, $\mathrm{m}$ & & \multirow[t]{19}{*}{ Test speed, $\mathrm{m} / \mathrm{s}$} \\
\hline 1 & & & 5 & 100 & & \\
\hline 2 & & & 5 & 200 & & \\
\hline 3 & & & 5 & 600 & & \\
\hline 4 & & & 10 & 100 & & \\
\hline 5 & & & 10 & 200 & & \\
\hline 6 & & & 10 & 600 & & \\
\hline 7 & & & 20 & 100 & & \\
\hline 8 & & & 20 & 200 & & \\
\hline 9 & & & 20 & 600 & & \\
\hline 10 & & & 5 & 100 & & \\
\hline 11 & & & 5 & 200 & & \\
\hline 12 & & & 5 & 600 & & \\
\hline 13 & & & 10 & 100 & & \\
\hline 14 & & & 10 & 200 & & \\
\hline 15 & & & 10 & 600 & & \\
\hline 16 & & & 20 & 100 & & \\
\hline 17 & & & 20 & 200 & & \\
\hline 18 & & & 20 & 600 & & \\
\hline
\end{tabular}


$\varnothing 9.8 \times 20 \mathrm{~mm}$ dimensions, before coating operations were performed. Surfaces were grinded with 100, 200, 400, 800, and 1200 mesh $\mathrm{SiO}_{2}$ sandpaper and then polished in order for the surface roughness of all samples to be the same. The average roughness $(\mathrm{Ra})$ values were obtained about $0.03 \mu \mathrm{m}$ for uncoated specimens.

The Nano-TiN coating process to the cleaned surface of the samples was carried out by cathodic-arc PVD method using $200 \mathrm{~V}$ voltage, $350{ }^{\circ} \mathrm{C}$ temperature, $4 \times 10^{-4} \mathrm{mbar}$ pressure, and $50 \mathrm{~A}$ current application conditions. The coating operations were done by Nanolin Surface Coating Technologies (Istanbul, Turkey).

The wear tests were carried out using a pin-on-disc test machine in accordance with ASTM standard G99 under dry sliding conditions. Before carrying out the abrasion test, the weight of the samples was first measured with a precision scale $( \pm 0.001 \mathrm{~g})$. The coated and uncoated samples were subjected to an abrasive wear test against sandpaper with 220 mesh under 3 different loads $(5,10$, and $20 \mathrm{~N}$ ). The tests were applied at three different sliding distances $(100 \mathrm{~m}, 200 \mathrm{~m}$, and $600 \mathrm{~m})$ keeping the sliding speed as constant at $2,6 \mathrm{~m} / \mathrm{s}$. At the end of each abrasion test, the samples were washed with alcohol, dried, and weighed. The average of 3 experimental results for each condition was taken. The coating status of the samples and wear test conditions are shown in Table 2. All the wear tests were conducted in an ambient environment, at a temperature of $25^{\circ} \mathrm{C}$ and a relative humidity of $30 \%$.

Schottky Field Emission Scanning Electron Microscope (FESEM) with high vacuum mode (HV) $(\leq 10-6 \mathrm{mbar})$ in ILTAM (Pamukkale University Advanced Material Research Centre) was used to be carried out the characterization of the coating before and after wear tests. Thanks to the mapping feature (EDS), information about the distribution of the elements in the sample also can be obtained via FESEM.

Considering weight loss, the wear rate $\left(\mathrm{Wr}, \mathrm{mm}^{3} / \mathrm{Nm}\right)$ of each specimen is evaluated using the Equation 1 [17]. $\Delta \mathrm{m}$, $\mathrm{d}$, Fn, and $\mathrm{S}$ denote wear loss $(\mathrm{g})$, density $\left(\mathrm{g} / \mathrm{mm}^{3}\right)$, load $(\mathrm{N})$, and sliding distance $(\mathrm{m})$, respectively.

$\mathrm{Wr}=\Delta \mathrm{m} / \mathrm{d}^{*} \mathrm{Fn} \mathrm{n}^{* \mathrm{~S}}$

\section{Results and Discussions}

\section{I. Microstructural characterization with FESEM and SEM-EDS}

Figure 1 presents the FESEM micrograph of the polished uncoated AISI D3 steel. The surface of nano-TiN coated AISI D3 steel's microstructures can be seen in Figure 2 at different magnifications. A TiN coating of less than 100 $\mathrm{nm}$ in size was obtained throughout the coating. A typical SEM-EDS analysis of the resulting coating is shown in Figure 3. Referring to the analysis of the results, $\mathrm{Fe}, \mathrm{N}$, $\mathrm{Ti}$, and $\mathrm{Cr}$ contents detected by EDS analysis were found

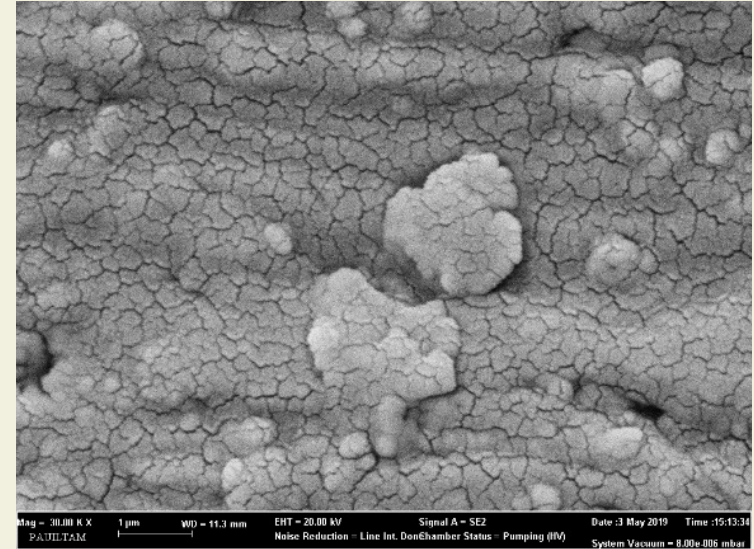

Figure 1. FESEM micrograph of uncoated AISI D3 steel
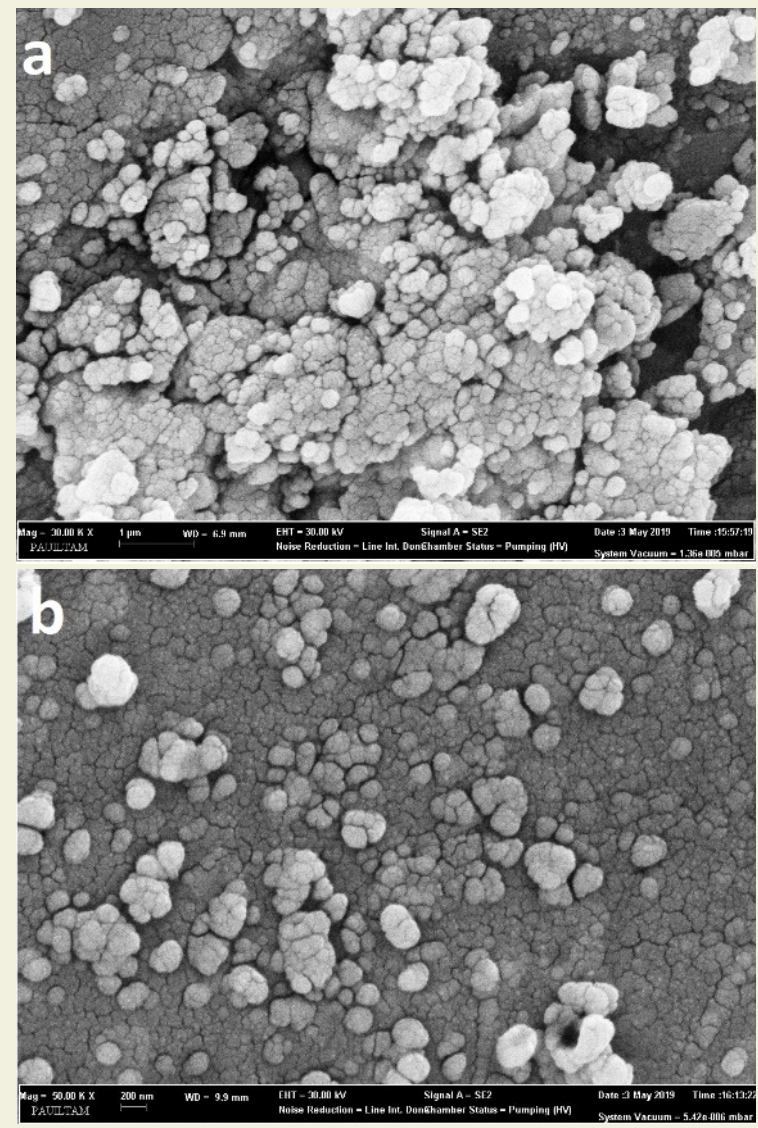

Figure 2. FESEM microstructures of nano-TiN coated AISI D3 steel (a) $30000 x$ (b) 50000x

respectively in weight $\%$ as $54.62,20.84,17.22$, and 7.32 . It can be said according to these results that $\mathrm{TiN}$ and $\mathrm{Fe}$ and $\mathrm{Cr}$ based nitride compounds were formed.

When the entire surface of the coating is examined areal and point wise, different formations have been detected in some regions (Figure 4). TiC (Figure 4a-d) and Ti-Cr (Figure 4e-f) based formations were detected in places from 1 micrometer to nanoscale, since AISI D3 tool steel has high $\mathrm{C}$ and $\mathrm{Cr}$ contents.

\subsection{Wear tests results}

Figure $5 \mathrm{a}$ and Figure $5 \mathrm{~b}$ show the wear losses of uncoated and coated materials, respectively. It was observed that, 


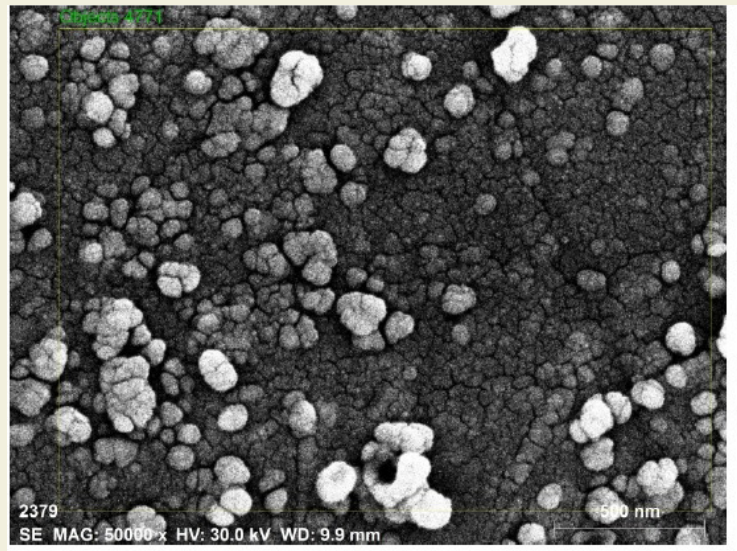

Figure 3. SEM-EDS field analysis of nano-TiN coated steel
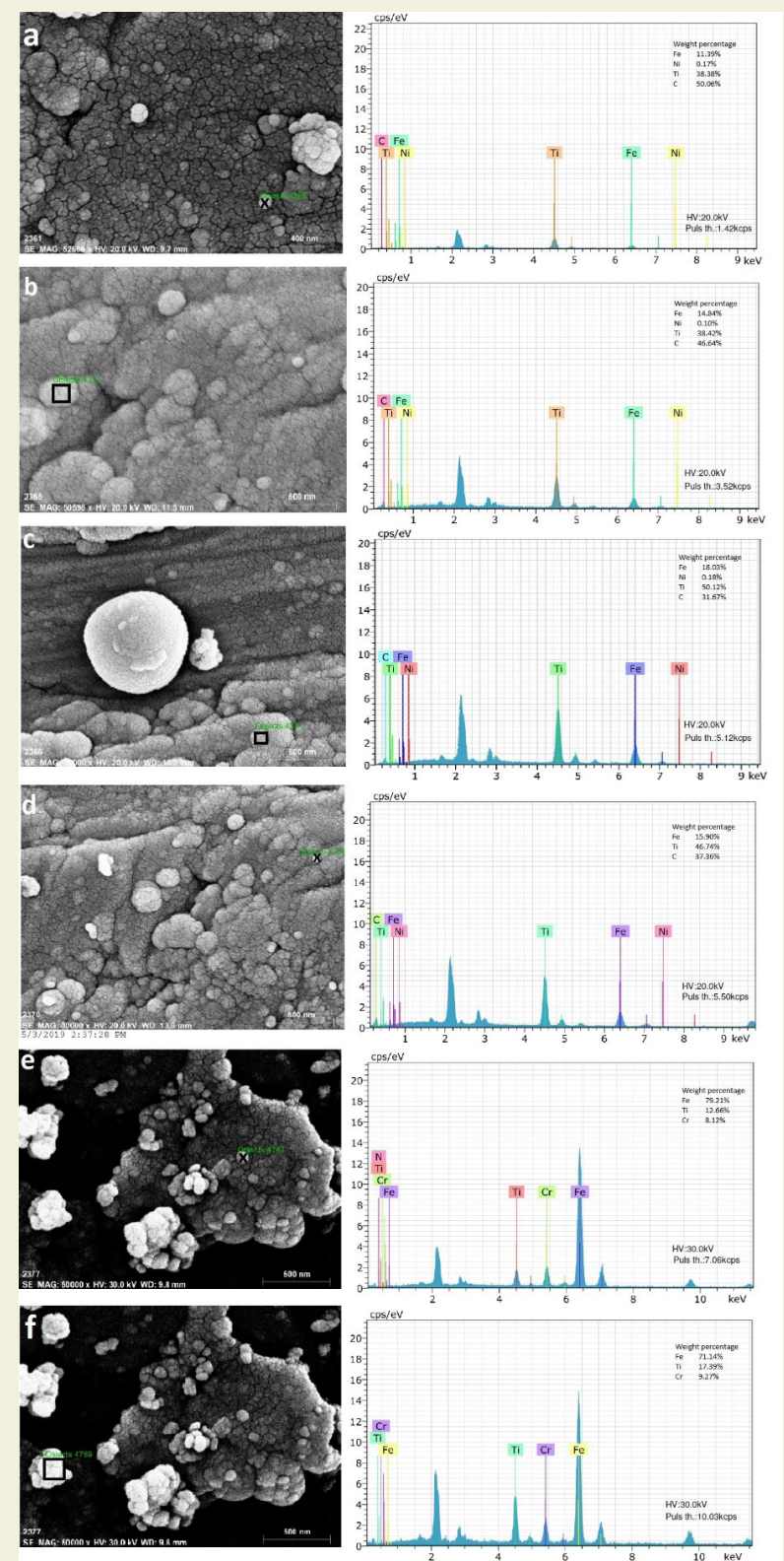

Figure 4. SEM-EDS spectrum with the respective test areas and points of coated sample

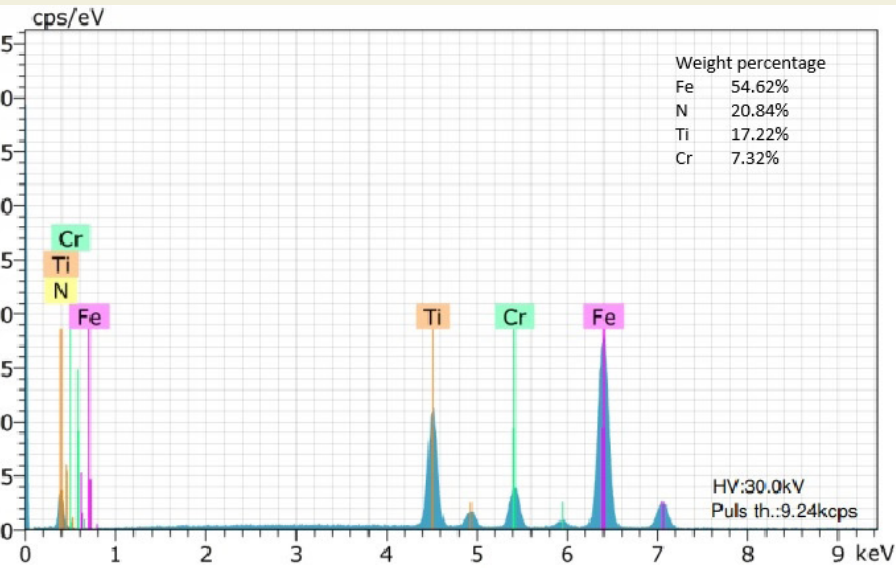

while load and sliding distance were increased, the wear loss was increased for both coated and uncoated specimens. For uncoated samples, with the increasing amount of load, proportionally the largest wear loss occurred at a distance of $100 \mathrm{~m}$ despite the shortest sliding distance. With the increasing load from $5 \mathrm{~N}$ to $10 \mathrm{~N}$ and $20 \mathrm{~N}$, the approximate wear loss increased by 10 and 8.5 times, respectively. With the sliding distance increasing from $100 \mathrm{~m}$ to $200 \mathrm{~m}$ and $600 \mathrm{~m}$, the wear loss also increased rapidly from $0.2 \mathrm{mg}$ to $2.2 \mathrm{mg}$ and $18 \mathrm{mg}$ under $5 \mathrm{~N}$ load. The biggest wear loss was determined as $26 \mathrm{mg}$ under 600 $\mathrm{m}$ slip distance and $20 \mathrm{~N}$ load. In coated samples, with the increasing amount of load, proportionally the largest wear loss occurred at a distance of $100 \mathrm{~m}$ despite the shortest sliding distance like uncoated samples. With the increasing load from $5 \mathrm{~N}$ to $10 \mathrm{~N}$ and $20 \mathrm{~N}$, the approximate wear loss increased by 2.2 and 12.2 times, respectively. With the sliding distance increasing from $100 \mathrm{~m}$ to $200 \mathrm{~m}$ and $600 \mathrm{~m}$, the wear loss also increased rapidly from $0.1 \mathrm{mg}$ to $1.8 \mathrm{mg}$ and $14 \mathrm{mg}$ under $5 \mathrm{~N}$ load. The biggest wear loss was determined as $20 \mathrm{mg}$ under $600 \mathrm{~m}$ slip distance and $20 \mathrm{~N}$ load. Compared to the coated and uncoated samples, the wear loss values obtained in the coated samples at sliding distances of $100 \mathrm{~m}$ and $200 \mathrm{~m}$ differed greatly from uncoated samples, under the same conditions almost $100 \%$. However, when the sliding distance reached $600 \mathrm{~m}$, the gap started to close and the gap decreased to $30 \%$. It can be said that the obtained nano-TiN layer was worn via increasing both the sliding distance and the load. As a result, the abrasive surface almost directly contacted the base material, and the wear rate was increased.

Figure 6 shows the variation of the calculated wear rates depending on the sliding distance (a) and the applied load (b). For uncoated samples, the wear rate was increased under $5 \mathrm{~N}$ and $10 \mathrm{~N}$ loads as increasing sliding distance. On the other hand, under $20 \mathrm{~N}$ load, although the sliding distance increases, the wear rate tends to decrease. As seen in Figure $7 \mathrm{e}$, it can be said that adhesion formed due to material agglomerations and increased surface roughness values reduces this rate. It is seen that the wear resistance of 


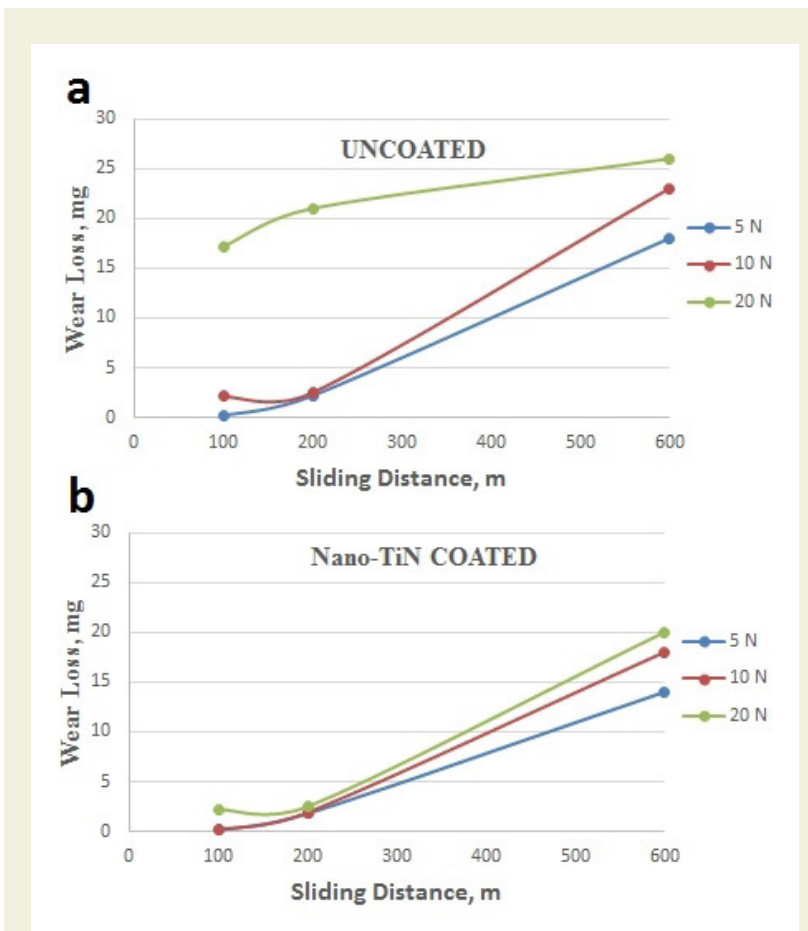

Figure 5. Wear loss of uncoated (a) and coated (b) samples

the nano-TiN coated samples increases significantly with the increasing load and sliding distance compared to the uncoated samples. Under the same wear conditions, the wear rate of the coated samples decreased up to 15 times. Although it has a nano sized thickness, it can be said that the contribution of TiN coating to the wear performance is quite high.

SEM images of worn surfaces can be seen in Figure 7. Figure 7 (a) presents the worn surface of uncoated samples under the conditions of $5 \mathrm{~N}$ wear load and $100 \mathrm{~m}$ sliding distance. Wear occurred on the surface in the form of very

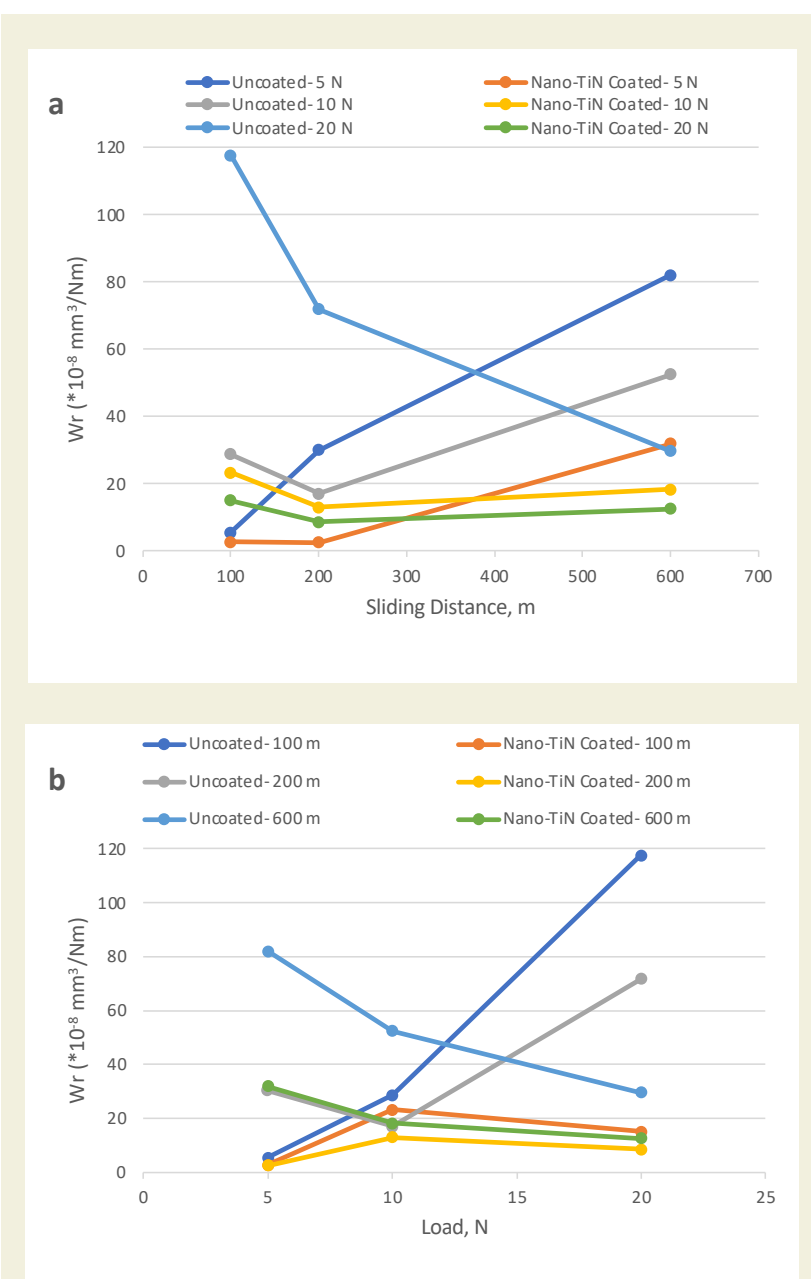

Figure 6. The variation of the wear rates depending on the sliding distance (a) and the applied load (b)

light and narrow wear marks. For coated samples (Figure 7 (b)), under $5 \mathrm{~N}$ load and $100 \mathrm{~m}$ sliding distance con-
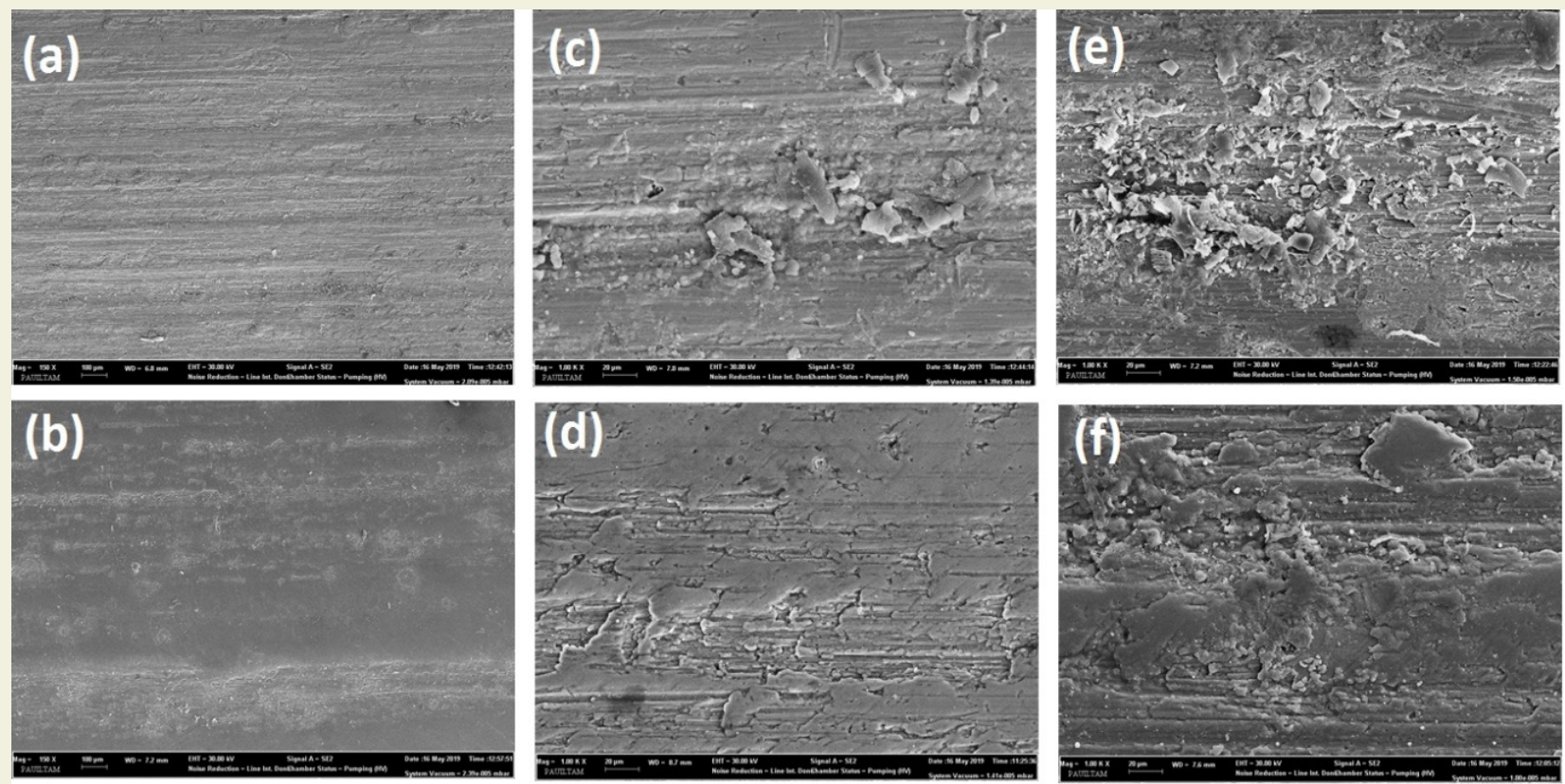

Figure 7. SEM images of worn surfaces (a) Uncoated/5 N/100 m, (b) Coated/5 N/100 m, (c) Uncoated/10 N/200 m, (d) Coated/10 N/200 m, (e) Uncoated/20 N/600 m, (f) Coated/20 N/600 m 


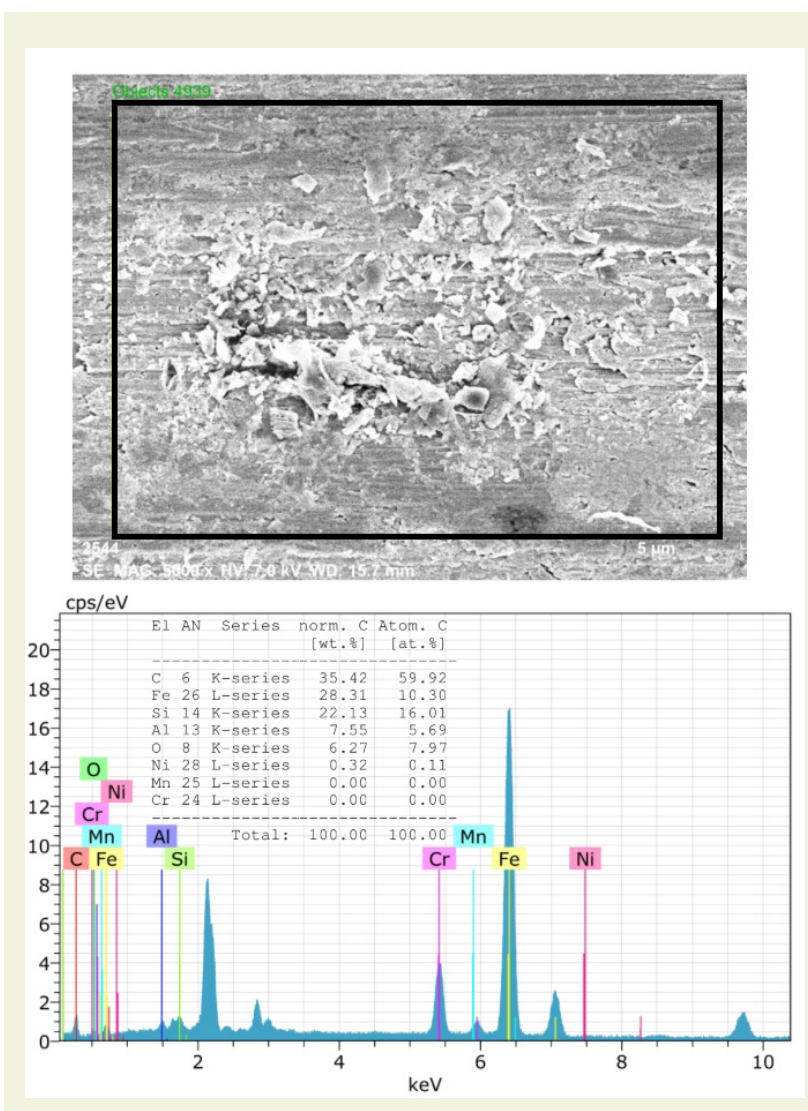

Figure 8. SEM-EDS analysis of uncoated worn surfaces under $20 \mathrm{~N}$ load and $600 \mathrm{~m}$ sliding distance conditions

ditions, obviously, wear tracks occurred slightly less than the uncoated sample. While load and sliding distance increased, the wear tracks have become much more pronounced. Figure 7 (c) presents the uncoated specimen's worn surface under the conditions of $10 \mathrm{~N}$ load and 200 $\mathrm{m}$ sliding distance. It can be seen that the wearing tracks become much clearer and the material is piled up in some areas. This result can be interpreted as the parts that are broken by the abrasion effect cannot be removed from the wear zone and stick to the surface again. Under the same conditions, for the coated sample (Figure 7 (d)), agglomerations are less noticeable. As well as the surface was less worn than the uncoated sample, the coating was still in place, and has not been lifted. Under the conditions of 20 $\mathrm{N}$ load and $600 \mathrm{~m}$ wear distance, which are the most severe conditions of the wear tests, excessive wear tracks and lumps were observed in both uncoated (Figure 7 (e)) and coated (Figure 7 (f)) samples.

These results were confirmed by SEM-EDS field analysis. In Figure 8, SEM-EDS analysis of uncoated sample's surface under $20 \mathrm{~N}$ load and $600 \mathrm{~m}$ sliding distance conditions. The order of the elements by weight is as follows: $35.42 \% \mathrm{C}, 28.31 \% \mathrm{Fe}, 22.13 \% \mathrm{Si}, 7.55 \% \mathrm{Al}, 6.27 \% \mathrm{O}$, and $0.32 \% \mathrm{Ni}$.

SEM-EDS analysis of coated sample's surface under $20 \mathrm{~N}$ load and $600 \mathrm{~m}$ sliding distance conditions can be seen in Figure 9. However, it still appears in SEM-EDS analyses that the layer was not fully worn. It can be seen in Fig- ure 8 that the parts with degenerate and agglomeration mainly contain Ti. Although the structure of the layer was impaired, $\mathrm{Ti}$ in the ratio of $98.75 \%$ and $\mathrm{N}$ in the ratio of $0.06 \%$ were found in the field analysis. In point analysis (Figure 10), although $\mathrm{Ti}$ is predominantly observed, C, Si, $\mathrm{O}$, and other alloying elements were detected, and at some points no $\mathrm{N}$ was detected. The order of the elements by weight is as follows: $83.23 \% \mathrm{Ti}, 6.74 \% \mathrm{C}, 5.38 \% \mathrm{Si}, 0.87 \%$ $\mathrm{Cr}$, and $0.74 \% \mathrm{Mn}$.
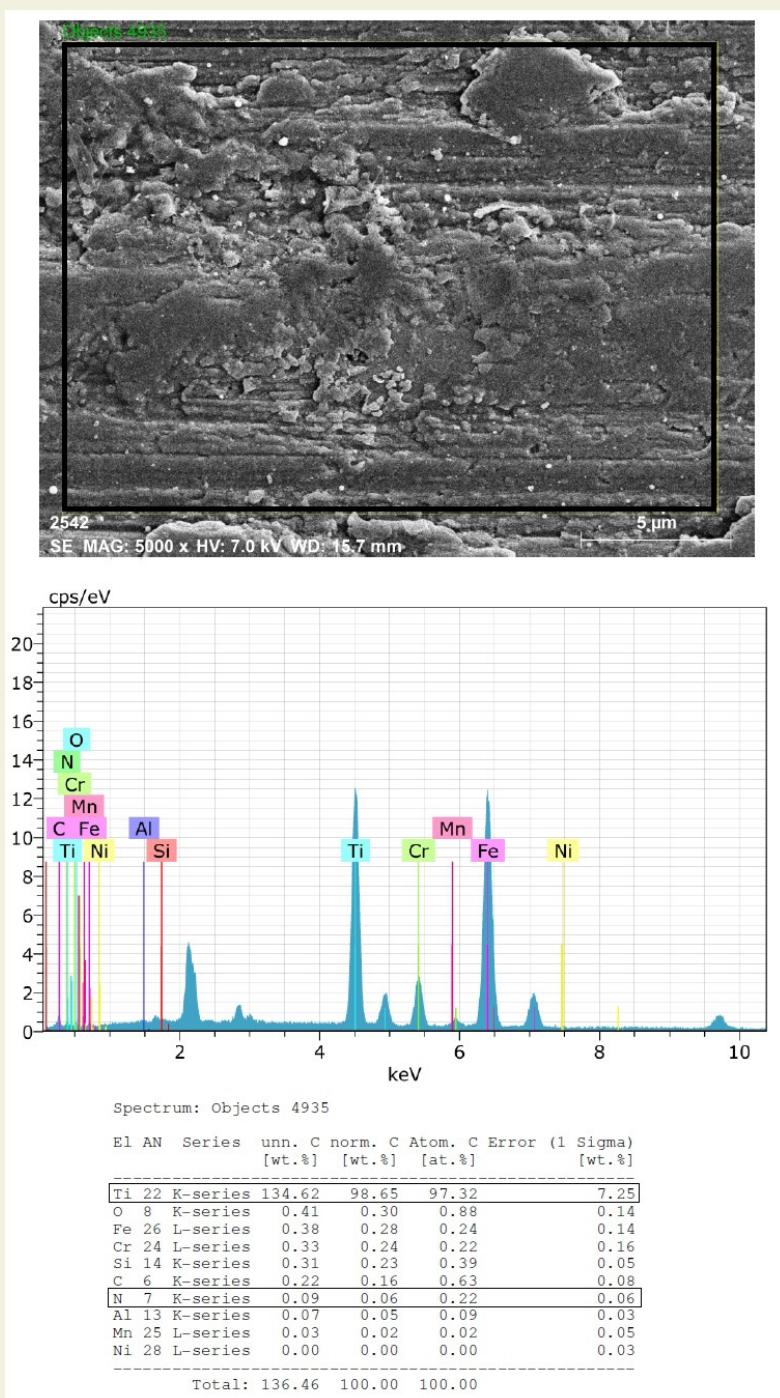

Figure 9. SEM-EDS field analysis of nano-TiN coated worn surfaces under $20 \mathrm{~N}$ load and $600 \mathrm{~m}$ sliding distance conditions

As a result, even under very severe and abrasive wear conditions, the nano-TiN coating fulfilled its task of increasing wear resistance. When the coated and uncoated samples are compared, the wear loss values obtained in the coated samples differ greatly from uncoated samples, under the same conditions almost $100 \%$. However, when the sliding distance reached $600 \mathrm{~m}$, the wear loss between coated and uncoated samples started to close and the gap decreased to $30 \%$. When the wear surfaces of the coated samples are examined, the elemental distribution in the wear zone is completely different from uncoated samples, 


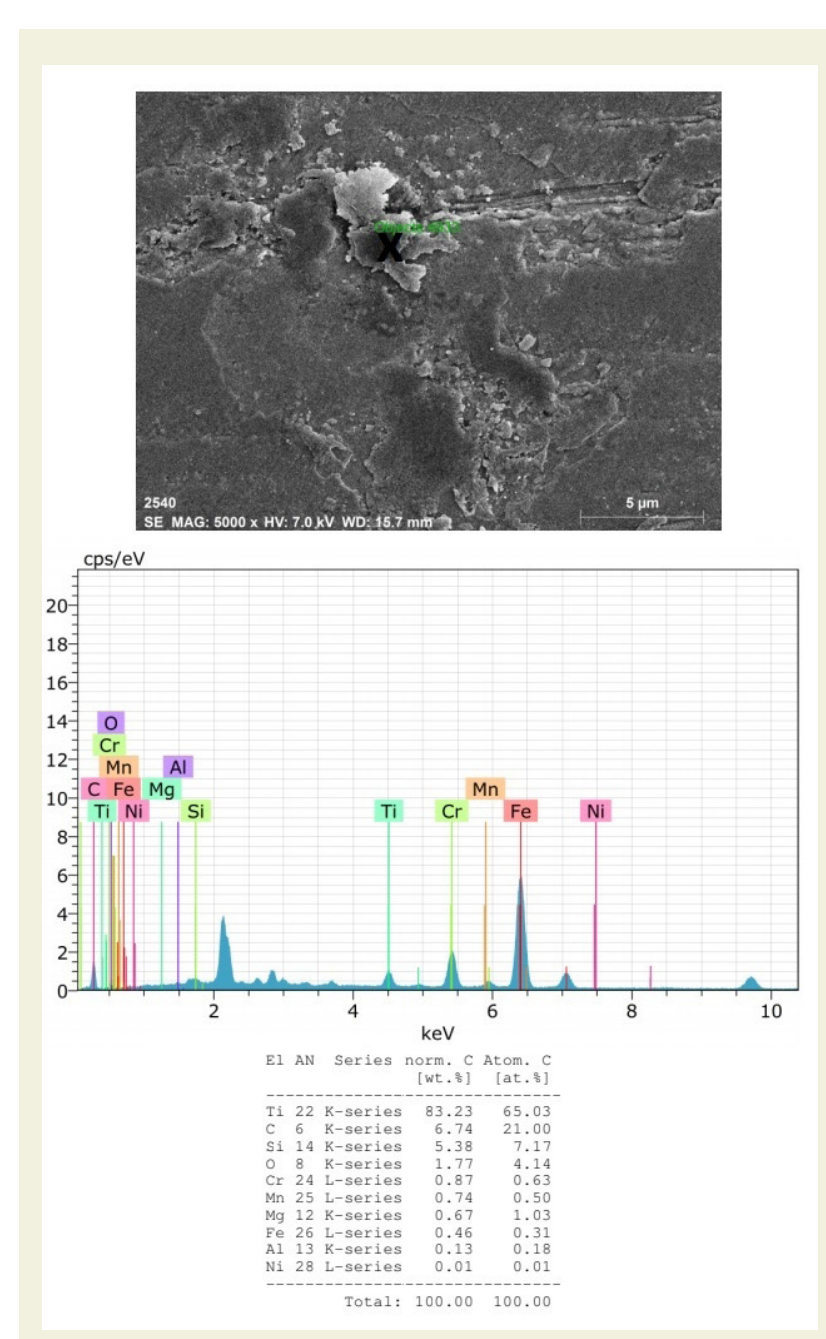

Figure 10. SEM-EDS point analysis of nano-TiN coated worn surfaces under $20 \mathrm{~N}$ load and $600 \mathrm{~m}$ sliding distance conditions

although the majority of the layer disappears.

\section{Conclusions}

In this study, AISI D3 tool steel was coated by a nano-TiN layer. Coated and uncoated samples were subjected to abrasive wear tests against 220 mesh sandpaper under 3 different loads $(5,10$, and $20 \mathrm{~N})$. The tests were applied at three different sliding distances $(100 \mathrm{~m}, 200 \mathrm{~m}$, and 600 $\mathrm{m})$ keeping the sliding speed as constant at $2.6 \mathrm{~m} / \mathrm{s}$. The microstructures of worn surfaces were examined by FESEM and SEM-EDS. The obtained results can be summarized as below:

- -Nano-TiN coating process was carried out by cathodic-arc PVD method on AISI D3 tool steel.

- -A nano-TiN coating of less than $100 \mathrm{~nm}$ in size was obtained throughout the coating.

- - For uncoated samples, while the applied load increased from $5 \mathrm{~N}$ to $20 \mathrm{~N}$, the wear loss was increased by 2.2 and 12.2 times.

- -For nano-TiN coated samples, with the increasing load from $5 \mathrm{~N}$ to $20 \mathrm{~N}$, the approximate wear loss increased by 10 and 8.5 times, respectively.
- -The wear loss values obtained in the coated samples at sliding distances of $100 \mathrm{~m}$ and $200 \mathrm{~m}$ differed greatly from uncoated samples, under the same conditions almost $100 \%$.

- -When the sliding distance reached $600 \mathrm{~m}$, the gap started to close and the gap decreased to $30 \%$.

- - Although the wear rate was increased under $5 \mathrm{~N}$ and $10 \mathrm{~N}$ loads as increasing sliding distance for uncoated samples, the wear rate tends to decrease under $20 \mathrm{~N}$ load.

- -The wear resistance of the nano-TiN coated samples is increased significantly with the increasing load and sliding distance compared to the uncoated samples.

- -Under the same wear conditions, the wear rate of the coated samples decreased up to 15 times.

-Under very severe wear conditions, the nano-TiN coating fulfilled its task of increasing wear resistance.

-When the wearing surfaces are analysed elementally, differences were detected in the chemical analysis of coated and uncoated samples.

\section{Rererences}

[1] Bunshah, R.F., Weissmantel, C. (2001). Handbook of Hard Coatings: Deposition Technologies, Properties and Applications. Noyes Publications, Norwich, New York.

[2] Bunshah, R.F. (1994). Vapor Deposition Technologies. Bunshah, R.F. (Ed.), Handbook of Deposition Technologies for Films and Coatings: Science, Technology, and Applications. William Andrew, LLC Norwich, New York, 4-72.

[3] Mattox D.M. (2010). Handbook of Physical Vapor Deposition (PVD) Processing. William Andrew, LLC Norwich, New York.

[4] Bunshatta, R.F. (1980). High Rate Physical Vapour Deposition Processes. Agard Lecture Series No: 106, Material Coating Techniques. Hardford House, London.

[5] Totten, G. E. (Ed.) (1992). ASM Handbook, Volume 18: Friction, Lubrication, and Wear Technology. ASM International, Cleveland.

[6] Gerth, J., Wiklund, U. (2008). The influence of metallic interlayers on the adhesion of PVD TiN coatings on high-speed steel. Wear, 264(9-10), 885-892, https://doi.org/10.1016/j. wear.2006.11.053.

[7] Aihua, L., Jianxin, D., Haibing, C., Yangyang, Jun, C.Z. (2012). Friction and wear properties of TiN, TiAIN, AITiN and CrAIN PVD nitride coatings. International Journal of Refractory Metals and Hard Materials, 31, 82-88. https://doi. org/10.1016/j.ijrmhm.2011.09.010.

[8] Chavda, M.R., Dave, D.P., Chauhan, K.V., Rawal, S.K. (2016). Tribological characterization of TiN coatings prepared by sputtering. Procedia Technology, 23, 36-41, https://doi. org/10.1063/1.5032487.

[9] Wang, L., Northwood, D.O., Nie, X., Housden, J., Spain, E., Leyland, A., Matthews, A. (2010). Corrosion properties and contact resistance of $\mathrm{TiN}, \mathrm{TiAIN}$ and $\mathrm{CrN}$ coatings in simulated proton exchange membrane fuel cell envi- 
ronments. Journal of Power Sources, 195, 12, 3814-3821, https://doi.org/10.1016/j.jpowsour.2009.12.127.

[10] Işıtan, A. (2018). Macro, Micro, Nano. Ersöz, M. Işıtan, A. Balaban, M. (Eds). Nanotechnology 1: Fundamentals of Nanotechnology. Bilal Ofset, Denizli, Turkey, 1-5.

[11] Abdel-Karim, R., Waheed, A.F. (2013). Nanocoatings. Aliofkhazraei, M. (Ed.), Modern Surface Engineering Treatments. IntechOpen, London, 123-140.

[12] Marani, S.M., Shahgholi, G., Moinfar, A. (2019). Effect of nano coating materials on reduction of soil adhesion and external friction. Soil and Tillage Research, 193, 42-49, https://doi.org/10.1016/j.still.2019.05.026.

[13] Vereschaka, A.A., Mokritskii, B.Y., Sitnikov, N.N., Oganyan, G.V., Aksenenko, A.Y. (2017). Study of mechanism of failure and wear of multi-layered composite nano-structured coating based on system Ti-TiN-(ZrNbTi) $\mathrm{N}$ deposited on carbide substrates. Journal of Nano Research, 45, 110-123, https://doi.org/10.4028/www.scientific.net/JNanoR.45.110.

[14] Wang, Y., Lin, Y. (2018). Study on the performance of nano-titanium nitride-coated stainless steel electrodes in electro-Fenton systems. Nanomaterials, 8(7), 494, https:// doi.org/10.3390/nano8070494.

[15] Groover, M.P. (2007). Fundamentals of Modern Manufacturing: Materials Processes, and Systems. John Wiley \& Sons, New York.

[16] Moganapriya, C., Vigneshwaran, M., Abbas, G., Ragavendran, A., Ragavendra, V.H., Rajasekar, R. (2021). Technical performance of nano-layered CNC cutting tool insertsAn extensive review. Materials Today: Proceedings, 45, 663-669, https://doi.org/10.1016/j.matpr.2020.02.731.

[17] Thankachan, T., Prakash, K. S., Kavimani, V., Silambarasan, S. R. (2021). Machine learning and statistical approach to predict and analyze wear rates in copper surface composites. Metals and Materials International, 27(2), 220-234, https://doi.org/10.1007/s12540-020-00809-3. 